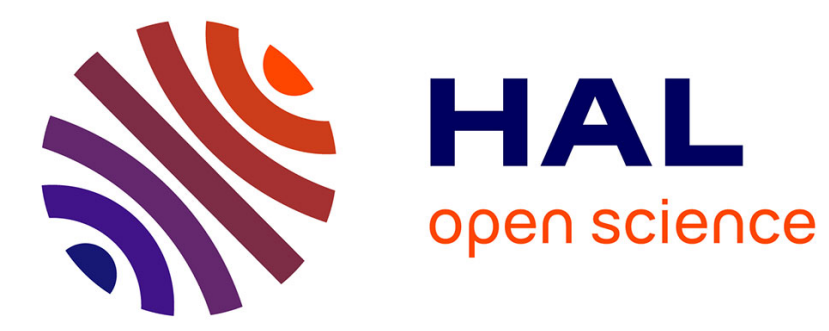

\title{
Schwann cells: Rescuers of central demyelination
}

Beatriz Garcia-diaz, Anne Baron-van Evercooren

\section{To cite this version:}

Beatriz Garcia-diaz, Anne Baron-van Evercooren. Schwann cells: Rescuers of central demyelination.

Glia, 2020, 68 (10), pp.1945-1956. 10.1002/glia.23788 . hal-02988052

\section{HAL Id: hal-02988052 \\ https: / hal.sorbonne-universite.fr/hal-02988052}

Submitted on 4 Nov 2020

HAL is a multi-disciplinary open access archive for the deposit and dissemination of scientific research documents, whether they are published or not. The documents may come from teaching and research institutions in France or abroad, or from public or private research centers.
L'archive ouverte pluridisciplinaire HAL, est destinée au dépôt et à la diffusion de documents scientifiques de niveau recherche, publiés ou non, émanant des établissements d'enseignement et de recherche français ou étrangers, des laboratoires publics ou privés. 


\section{Schwann cells: Rescuers of central demyelination.}

Beatriz Garcia-Diaz ${ }^{1,2}$, and Anne Baron-Van Evercooren*2.

${ }^{1}$ Unidad de Gestión Clínica de Neurociencias, IBIMA, Hospital Regional Universitario de Málaga, Universidad de Málaga, Spain.

${ }^{2}$ Institut du Cerveau et de la Moelle Epinière-Groupe Hospitalier Pitié-Salpêtrière, INSERM, U1127, CNRS, UMR 7225, F-75013 Paris; Sorbonne Universités, Université Pierre et Marie Curie Paris 06, UM75, F-75005 Paris, France.

*Corresponding authors: Beatriz Garcia Diaz (Phone: +33 10 (0) 157274170 ; e-mail: beatriz.garcia@icm-institute.org) and Anne Baron Van-Evercooren (Phone : +33 (0) 157274123 ; e-mail: anne.baron@upmc.fr

\section{ACKNOWLEDGMENTS}

We thank the National Multiple Sclerosis Society (NMSS), to A.B. INSERM, CNRS, ARSEP, and the program "Investissements d'Avenir" (ANR-10- IAIHU-06) to AB; and Junta de Andalucía and the European Commission under the Seventh Framework Program of the European Union (agreement Num. 291730, contract TAHUB-II-107) to B.G-D for having support our work on Schwann cells. We also thank past and present members of the laboratory and collaborators for their valuable contributions.

\section{CONFLIC TO INTEREST}

The authors declare that they have not conflict of interest.

\section{WORD COUNT}

Abstract: 181 words, main text: 4328 words, and 114 references 


\begin{abstract}
The presence of peripheral myelinating cells in the central nervous system (CNS) has gained the neurobiologist attention over the years. Despite the confirmed presence of Schwann cells in the CNS in pathological conditions, and the long list of their beneficial effects on central remyelination, the cues that impede or allow Schwann cells to successfully conquer and remyelinate central axons remain partially undiscovered. A better knowledge of these factors stand out as crucial to foresee a rational therapeutic approach for the use of Schwann cells in CNS repair. Here, we review the diverse origins of Schwann cells into the CNS, both peripheral and central, as well as the CNS components that inhibit Schwann survival and migration into the central parenchyma. Namely, we analyze the astrocyte- and the myelin-derived components that restrict Schwann cells into the CNS. Finally, we highlight the unveiled mode of invasion of these peripheral cells through the central environment, using blood vessels as scaffolds to pave their ways towards demyelinated lesions. In short, this review presents the so far uncovered knowledge of this complex CNS-peripheral nervous system (PNS) relationship.
\end{abstract}

\title{
Keywords
}

Schwann cells, central nervous system, remyelination, astrocytes, myelin, blood vessels.

\section{Main Points}

- Schwann cells, from PNS and CNS origin, are able myelinate demyelinated CNS.

- Schwann cells need to overcome inhibitory signals from astrocytes and CNS myelin to invade CNS.

- Blood vessels provide routes for their migration guided within CNS. 
The nervous system, although working as a sole system, is divided into two separated compartments: the central (CNS) and the peripheral (PNS) nervous systems, which differ in cellular compositions.

The CNS includes the optic nerve, brain and spinal cord, while the PNS consists mainly of nerves. The CNS and PNS converge at the motor exit points (MEP) and at the dorsal root entry zones (DREZ), where transition zones draw the limit of both systems and segregate the CNS and PNS cellular components. These boundaries seal off neurons as well as central and peripheral glia (Fraher, 1999; Fraher \& Kaar, 1986), leaving only space dorsally for PNS axon entry, and ventrally for CNS axon exit.

Due to the mentioned compartmentalization, different glial cells share to some extent, similar roles in both systems. Regarding myelination, oligodendrocytes are the cells in charge of forming the myelin sheaths in the CNS, while Schwann cells (in mammals), and MEP glia (in zebrafish) perform this same function in the PNS (Emery, 2010; Fraher \& Rossiter, 1983; Jessen \& Mirsky, 2005). Despite the successful maintenance of the correct composition in both systems, some examples of transgression by Schwann cells or oligodendrocytes (Coulpier et al., 2011) have been reported both in normal and pathological conditions. This review is dedicated to our understanding of Schwann cell presence in the CNS.

\section{Schwann cell presence in the CNS.}

The ectopic presence of Schwann cells within the CNS has been extensively described over the years. Schwann cell presence in the human CNS, was first highlighted by Adelman and Aronson (Adelman \& Aronson, 1972), and later, in the non-human primate CNS (Raine, 1976). This PNS-CNS transgression capacity of the endogenous Schwann cells was experimentally challenged in different demyelinating models including experimental autoimmune encephalomyelitis (Raine, Traugott, \& Stone, 1978), viral encephalomyelitis (Dal Canto \& Lipton, 1980), focal myelinotoxic injections (Blakemore, 1982), and focal compressive/contusive lesions of the spinal cord (Blight \& Young, 1989; Griffiths \& McCulloch, 1983), demonstrating the capacity of endogenous (as opposed to grafted, exogenous) Schwann cells to colonize the CNS under pathological conditions.

The presence of these endogenous Schwann cells in the CNS opened the question of how and why this transgression occurs, and introduced the idea of the ability of Schwann cells to rescue the lesioned CNS. Advocating this notion, a large number of Schwann cells were also found myelinating CNS axons in human pathological conditions, such as multiple sclerosis (Itoyama, Ohnishi, Tateishi, Kuroiwa, \& Webster, 1985; Itoyama, Webster, Richardson, \& Trapp, 1983; Yamamoto, Kawamura, Hashimoto, \& Nakamura, 1991) or spinal cord injury (Bunge, 1993; J. D. Guest, Hiester, \& Bunge, 2005; Wang, Walter, \& Gerhard, 1996) as well as in long-lived rodent and canine myelin mutant (Duncan \& Hoffman, 1997). In these mutants, Schwann cells were mainly found in the spinal cord, they were also present in the forebrain, brain stem, and cerebellum.

\section{Origin of the Schwann cell presence in CNS.}

For decades, these CNS remyelinating Schwann cells were considered to arise from outside the CNS (Franklin \& Blakemore, 1993; Gilmore, 1971; Gilmore, Sims, \& Heard, 1982; Jasmin, Janni, Moallem, Lappi, \& Ohara, 2000; Sims, Durgun, \& Gilmore, 1998), with neural crest-derived Schwann cells migrating from the PNS into the CNS to contribute to myelin repair. In this situation, Schwann cells would need to trespass the PNS-CNS transition zone. However, the recent developments of genetic 
tools allowed digging into the source of these cells and demonstrated that their origin is not solely peripheral (Assinck et al., 2017; Ma et al., 2018; Zawadzka et al., 2010).

As thought before, genetic fate mapping studies have proven that peripheral non-myelinating and myelinating Schwann cells are recruited from the periphery into the CNS where they provide axons with peripheral myelin, thus implying their ability to migrate and cross the CNS-PNS border to provide ensheathment to central axons (Assinck et al., 2017; Ma et al., 2018). Despite this expected observation, genetic tools have also revealed more surprising findings. Non-neural crest derived resident cells of the CNS, the oligodendrocyte precursor cells (OPC), are able to differentiate into remyelinating Schwann cells in response to spinal cord demyelination or injury (Zawadzka et al., 2010; Assinck et al., 2017). After spinal cord injury, Schwann cell myelin sheaths in the vicinity of the dorsal root entry zone, are typically derived from peripheral cells. However those myelinating Schwann cells at the epicentre of the lesion are derived from central OPC (Assinck et al., 2017). Interestingly, the number OPC-derived Schwann cells increases overtime indicating an ongoing production of Schwann cells by non-neural crest progenitors. In contrast, the number of neural crestderived Schwann cell does not change after the first days of remyelination, suggesting that the "outside-in" Schwann cell migration occurs only in the first steps of the lesion healing (Zawadzka et al., 2010; Assinck et al., 2017). These unexpected observations support the view that most of the myelinating Schwann cells present within CNS are derived from the OPC, which upon activation by micro-environmental cues via BMP/Wnt signaling, differentiate into Schwann cells (UlanskaPoutanen et al., 2018) and remyelinate central axons both in demyelinating lesions (Zawadzka et al., 2010) and spinal cord injury (Assinck et al., 2017).

Although increasing studies have addressed the ability of OPC to differentiate into myelinating Schwann cells, based on their expression of pre-myelinating (SCIP and OCT6) or myelinating Schwann cell markers (PO myelin protein or periaxin) (Zawadzka et al., 2010), their capacity to give rise to nonmyelinating Remak glia remains unexplored. Due to Schwann cell plasticity and their capacity of transdifferentiation between myelinating and non-myelinating Schwann cells under (Jessen \& Mirsky, 2019), it will be of interest to further elucidate whether CNS-resident Schwann cell conserve this capacity in the central environment. Nevertheless, new genetic tools to specifically label their lineage independently of their myelination ability will be required to investigate this question.

\section{Exogenous Schwann cells as potential candidates to enhance CNS remyelination}

A large number of pre-clinical studies using cell transplantation corroborated overtime Schwann cell great capacity to contribute to CNS repair. Engraftment of nerve fragments (Richardson, Issa, \& Shemie, 1982) first, and of purified Schwann cells later, highlighted the role of myelinating Schwann cells in promoting CNS axonal survival (Blakemore, Crang, \& Patterson, 1987; Pearse et al., 2007), long-term maintenance of normal distribution of sodium and potassium channels (Black, Waxman, \& Smith, 2006) and restoration of axonal conduction (Felts \& Smith, 1992). As a result, Schwann cell remyelination of experimental CNS lesions ultimately lead to functional rescue of neurological deficits (Blight \& Young, 1989; Deng, Walker, \& Xu, 2015; Girard et al., 2005; Jasmin et al., 2000). Furthermore, the list of Schwann cell beneficial effects in CNS repair is not restricted to their myelinating capacity, and includes axon growth promoting activities by the secretion of trophic factors including NGF and BDNF (Assouline et al., 1987; Bampton \& Taylor, 2005), expression on their membrane of permissive extracellular matrix (ECM) proteins such as laminin and fibronectin (BaronVan Evercooren, Kleinman, Seppa, Rentier, \& Dubois-Dalcq, 1982; Chiu, Espinosa de los Monteros, Cole, Loera, \& de Vellis, 1991), and a variety of adhesion molecules (NCAM, L1 etc) (Reichardt et al., 
1989). Recently, Wei and collaborators (Wei et al., 2019) unveiled the promising role of the exosomes produced by Schwann cells in repairing the CNS. These Schwann cell-secreted exosomes harbor proteins related to important CNS repair mechanisms, such as axon regeneration and inflammation inhibition. To date, the therapeutic use of Schwann cells, by exogenous transplantation, has been broadly explored in a variety of animal models of CNS diseases such as toxin-induced demyelination (Girard et al., 2005; Kocsis \& Waxman, 2007; Woodhoo et al., 2007), multiple sclerosis and spinal cord injury (Bastidas et al., 2017; Kanno, Pearse, Ozawa, Itoi, \& Bunge, 2015; Pearse et al., 2004; Sparling et al., 2015).

The idea of using Schwann cells to therapeutically enhance CNS myelin repair gained even more relevance due to the possibility of obtaining and expanding human and non-human primate Schwann cells (Avellana-Adalid et al., 1998; Casella, Bunge, \& Wood, 1996; Levi et al., 1995; Rutkowski, Kirk, Lerner, \& Tennekoon, 1995). Thus, these cells started being considered as promising candidates for autologous transplantation in CNS diseases (Anderson et al., 2017; Kocsis, Akiyama, Lankford, \& Radtke, 2002), avoiding concerns about immunological rejection of the grafted cells. Relieving any safety issues, pre-clinical studies showed that autologous Schwann cell transplantation could be a clinically safe approach to repair the CNS in rodents (Bastidas et al., 2017; J. Guest, Santamaria, \& Benavides, 2013; Pearse et al., 2004; Sparling et al., 2015) and non-human primates (Bachelin et al., 2005). To date, the therapeutic use of Schwann cells has been tested in clinical trials for spinal trauma (Anderson et al., 2017) (Clinical trial.gov: NCT01739023).

Despite these promising clinical effects, exogenous Schwann cell transplantation still opposes obvious limitations, hindering the possibility of complete success for these types of treatments. Although Schwann cells were found highly motile cells in vitro (Baron-Van Evercooren et al., 1982; Milner et al., 1997) and in vivo within the PNS (Cattin et al., 2015), they exhibit poor migration through the parenchyma, from their injection site once grafted in the CNS (Baron-Van Evercooren et al., 1992; Woodhoo et al., 2007). Their survival within the CNS parenchyma is also compromised (Iwashita \& Blakemore, 2000; Iwashita, Fawcett, Crang, Franklin, \& Blakemore, 2000). This poor migration and survival in the CNS is stage-dependent since more immature stages of the lineage, such as boundary cap cells (Zujovic et al., 2011) and Schwann cell precursors (Woodhoo et al., 2007) grafted in similar conditions survive and migrate more efficiently in the adult CNS parenchyma. These findings indicate that the CNS/PNS segregation is not exclusively due to a physical confinement of both compartments by the glia limitans and specialized glial cells, which together form the transitional zone (Fontenas \& Kucenas, 2018; Fraher, 1992) but rather to a more complex molecular and cellular inhibition from different CNS components.

\section{What prevents Schwann cells to successfully remyelinate the injured CNS?}

Hence, deciphering what prevents Schwann cells from extensively populate and myelinate CNS axons in physiological conditions, and what grants their incursion and survival under others, is of high relevance to myelin repair. Based on the original hypothesis of the exclusive peripheral origin of the CNS remyelinating Schwann cells, the main barrier preventing their invasion of the CNS, would be physical, and formed by astrocytes. However, despite this physical impediment, the migration failure of Schwann cells grafted into the CNS or centrally originated from OPCs to invade the system, indicates that other mechanisms ensure Schwann cell restriction from the CNS. 
Here, we will review the known aspects of Schwann cell exclusion from the CNS and their ability to overpass this inhibition under certain conditions. In particular, we will review Schwann cell interactions with the major CNS components: astrocytes, oligodendrocyte and/or myelin.

\section{Astrocyte}

In the mature spinal cord, astrocyte processes branch profusely and come to form the principal central nervous tissue component of the transition zone, and therefore, constitute the main component of the physical barrier between CNS and PNS, the glia limitans (Fraher, 1992). This astrocytic barrier is also found around blood vessels. As examples of their importance in delimiting both territories, ectopic entries of peripheral cells into the spinal cord are largely correlated with the disruption of astrocyte integrity in the mature nervous system (Blakemore \& Patterson, 1975; Duncan, Hammang, \& Gilmore, 1988; Duncan \& Hoffman, 1997; Franklin \& Blakemore, 1993).

In support of astrocyte inhibition, exogenous Schwann cells show poor survival and migration out of the site of injection, which is generally confined by reactive astrocytes (Andrews \& Stelzner, 2007; Baron-Van Evercooren et al., 1992; Duncan et al., 1988; Franklin \& Blakemore, 1993; Iwashita et al., 2000; Wilby et al., 1999). In contrast, endogenous (Woodruff \& Franklin, 1999) and exogenous Schwann cell remyelination (Shields, Blakemore, \& Franklin, 2000) is extensive in astrocyte-free areas. The astrocyte-Schwann cell exclusion also occurs during spontaneous remyelination in irradiated rats where astrocytes are ablated and Schwann cells conquer the territory (Blakemore \& Patterson, 1975; Gilmore et al., 1982; Heard \& Gilmore, 1980) .

This constraint is far from being exclusively physical. In vitro co-culture studies showed sharp boundaries between Schwann cells and astrocytes (Ghirnikar \& Eng, 1995; Lakatos, Franklin, \& Barnett, 2000; Wilby et al., 1999). This observation led to investigate about the molecular cues responsible for this repulsion. In this line, in vitro studies demonstrated that Schwann cell Ncadherin-mediated adhesion to astrocytes, trigger astrocyte hypertrophy, reducing Schwann cell migration within astrocyte-rich environments (Fairless, Frame, \& Barnett, 2005; Wilby et al., 1999). Moreover, Schwann cell-astrocyte contacts induce astrocytic-stress response consisting in cytoplasmic hypertrophy and elevated expression of GFAP, chondroitin sulfate proteoglycan (CSPG) and aggrecan (Fishman, Nilaver, \& Kelly, 1983; Ghirnikar \& Eng, 1994, 1995; Lakatos, Barnett, \& Franklin, 2003; Plant, Bates, \& Bunge, 2001; Santos-Silva et al., 2007). In turn, both CSPG and aggrecans block Schwann cell migration and induce the formation of a Schwann cell-astrocyte border line (Afshari, Kwok, \& Fawcett, 2010; Grimpe et al., 2005; Santos-Silva et al., 2007). Recently, Barnett and collaborators reported the presence of heparan sulfate proteoglycans (HSPG) in astrocyte ECM preventing Schwann cells to mingle with astrocytes, and sequestering the soluble neuregulin required for their migration (O'Neill et al., 2017). Finally, expression of NCAM by astrocytes and Schwann cells contributes to this borderline. Forced expression of the sialylated form of NCAM in Schwann cells hinders their self-self aggregation and promotes their migration and mixing with astrocytes in vitro (Bachelin, Zujovic, Buchet, Mallet, \& Baron-Van Evercooren, 2010; Lavdas, Franceschini, Dubois-Dalcq, \& Matsas, 2006). Furthermore, sialylation of NCAM on Schwann cells facilitates their migration in vivo, enhancing their recruitment and remyelination at the lesion site (Bachelin et al., 2010) and promoting functional recovery in spinal cord injury (Papastefanaki et al., 2007).

Other molecules responsible for Schwann cell-astrocyte segregation are the Eph/ephrin family (Afshari et al., 2010). Astrocytes producing ephrinA1, ephrinA3, and ephrinA5 inhibit Schwann cell migration on a laminin substrate. This response is mediated by the expression of the ephrin 
receptors EphA2, EphA4, and EphA7 in Schwann cell. In particular, blocking these inhibitory molecules by the soluble receptor EphA4-Fc enhances Schwann cell ability to migrate on and intermingle with astrocytes.

Astrocytes also hold a more indirect role in Schwann cell exclusion from the CNS. Beyond the role of astrocyte-derived inhibitory cues, activated astrocytes via STAT3, play a major role in determining the balance of OPC-derived oligodendrocytes vs. Schwann cells in favor of oligodendrocytes (Monteiro de Castro, Deja, Ma, Zhao, \& Franklin, 2015; Talbott et al., 2005), and thus counting as another mechanism to maintain the specific CNS cellular composition.

Myelin

Other CNS components that have been suggested as potential candidates to restrain Schwann cell migration across the CNS/PNS border are the mature oligodendrocytes and CNS-myelin. Yet, in myelin mutants, where myelin is defective but oligodendrocytes are still present (such as myelin deficient (md), taiep rats, and canine shaking (sh) pups), spontaneous Schwann cell invasion occurs into the dysmyelinated CNS (Duncan \& Hoffman, 1997). This pointed out that CNS-myelin, rather than oligodendrocytes, are the major players in Schwann cell exclusion from CNS white matter.

Several facts support this hypothesis. Langford and Owens (Langford \& Owens, 1990) made the first observation that Schwann cells transplanted into the demyelinated spinal cord avoid the white matter parenchyma when migrating towards the lesion. Grafting Schwann cells in wild-type and myelin mutant mice revealed that Schwann cells do not interact directly with myelin sheaths nor with mature oligodendrocytes in the wild-type white matter, but do so in the hypomyelinated white matter of MBP deficient-mice (Baron-Van Evercooren et al., 1996; Baron-Van Evercooren, DuhamelClerin, Boutry, Hauw, \& Gumpel, 1993). Yet these observations could have reflected the lack of compaction or altered composition of the mutant myelin.

While the poor migration and survival of exogenous Schwann cells within wild-type CNS white matter has been well documented over the years (Bachelin et al., 2010; Iwashita \& Blakemore, 2000; Iwashita et al., 2000), the molecular mechanisms involved in Schwann cells-myelin repellence was not addressed. We started to investigate on the potential mechanisms ruling this Schwann cellsmyelin inhibition, and discovered that two different myelin-associated inhibitors of axonal growth also negatively regulate Schwann cell migration (Chaudhry et al., 2017; Garcia-Diaz et al., 2019).

The first player in this negative interaction is the myelin-associated glycol protein (MAG) (Chaudhry et al., 2017). In collaboration with Marie Filbin's group, we found that MAG, as well as CNS myelin, is able to inhibit Schwann cell migration and induces cell death through the p75 neurotrophin receptor (p75NTR) in vitro. MAG interaction with p75NTR undergoes $\gamma$-secretase-dependent cleavage, which in turn inhibits Schwann cell migration and induces their death. This mechanism of action was validated in vivo, by transplanting Schwann cell remotely from a lesion. We also found that blocking p75 cleavage improved their migration, and consequently, their participation in CNS remyelination (Chaudhry et al., 2017).

Additionally, using different in vitro, ex vivo and in vivo paradigms, we recently demonstrated that EphrinB3, another myelin inhibitor of axonal growth (Duffy et al., 2012), plays an essential role in Schwann cell exclusion from the CNS (Garcia-Diaz et al., 2019). We showed that EphrinB3, through EphA4 and EphB6 receptors, impairs their adhesion and process extension onto myelin, and modulates their cellular adhesion to ECM such as fibronectin. Of relevance, expression of these receptors is reduced in more immature-like mutant Schwann cells expressing low levels of Krox20 (Le et al., 2005). This parallels with previous studies that correlated immature Schwann cell-lineage cells 
with a greater capacity of mingling and migration across white matter (Woodhoo et al., 2007; Zujovic et al., 2010). Nevertheless, whether expression of the Eph receptors by Schwann cells plays a role in the PNS/CNS segregation during development, and/or whether their down-regulation occurs after injury remains unknown.

\section{What facilitates Schwann cells to conquer the injured CNS?}

Despite the above-mentioned mechanisms of successful maintenance of the PNS-CNS compartmentalization, the presence of Schwann cells into the CNS in normal and pathological conditions is unquestionable (Adelman \& Aronson, 1972; Feigin \& Ogata, 1971; J. D. Guest et al., 2005; Itoyama et al., 1985; Itoyama et al., 1983; Raine, 1976; Yamamoto et al., 1991). Therefore, there must be some routes that enable Schwann cells to bypass the astrocyte and white matter inhibitory cues to invade the CNS under certain conditions. In this review, we will discuss a newly identified route of migration used by the Schwann cells to invade the CNS: the vascular network.

The presence of CNS axons remyelinated by Schwann cells, has been frequently described in close association with blood vessels in dysmyelinating (reviewed in (Duncan \& Hoffman, 1997)) or demyelinating conditions (Sims et al., 1998). PNS myelin was also found in the perivascular spaces, close to vessel at the spinal cord surface in response to spinal cord irradiation (Gilmore \& Sims, 1993, 1997). Moreover, various cell tracing paradigms highlighted the presence of exogenously introduced Schwann cells restricted to the meninges (Langford \& Owens, 1990), and more precisely, the subarachnoid Virchow-Robin perivascular spaces (Baron-Van Evercooren et al., 1996) or close to blood vessels within the brain parenchyma (Brook, Lawrence, \& Raisman, 1993; Raisman, Lawrence, \& Brook, 1993).

Although these studies evidenced Schwann cell-blood vessel interaction, they did not investigate the role of the blood vessel network in Schwann cells migration. To address this issue, we grafted Green fluorescent protein (GFP) expressing Schwann cells remotely form a focal lesion of the spinal cord of wild-type mice. Tissue clarification allowed visualization of the grafted cells en route to the lesion, that are in close contact with the blood vessel network (Fig. 1). The same grafting paradigm and exvivo live imaging showed Schwann cells sliding along each other on vessels and jumping from one vessel to another to reach the lesion. Furthermore electron microscopy indicated that perivascular Schwann cells in the CNS were localized between the perivascular end-feet and endothelial cells, and embedded in the perivascular ECM without making direct contacts with the endothelial cells (GarciaDiaz et al., 2019). Interestingly, Schwann cells also migrate along blood vessels in the injured nerve. However in the latter case, they migrate in direct contact with the endothelial cells rather than within the perivascular ECM (Cattin et al., 2015). Thus, despite the fact that Schwann cells share similar mechanisms to conquer both PNS and CNS injured nervous system, the different molecular and cellular environment existing between PNS and CNS, including different degrees of confinement are likely to result in the different migration modalities.

Upon arrival at the lesion site, Schwann cell affinity for axons released their association with blood vessels, as a first step towards myelin repair (Garcia-Diaz et al., 2019). While the above data were obtained with exogenous Schwann cells grafted remotely from a lesion, lineage specific tools combined with cell specific markers provided evidence that such a mechanism is shared with endogenous Schwann cells (Garcia-Diaz et al., 2019). However, whether these Schwann cells have a peripheral or central origin, or both, needs to be addressed further. 
Despite the newly elucidated role of blood vessels as Schwann cell cargos, whether they passively support Schwann cell migration, or whether they play a more active role remains to be solved. Launching the answer to this question, we provided the evidence first, for the absence of direct contact between Schwann cells and blood vessels thus ruling out a potential mechanical intervention of blood vessels in Schwann cell migration, and second, for the existence of vascular remodeling in the demyelinated area with a concomitant increase in ECM in response to demyelination (UlanskaPoutanen et al., 2018), as shown by a significant increase of collagen 4 and blood vessel network (Glut1 positive) after 5 days of lysolecithin-induced demyelinating lesions (Fig. 2). These changes may trigger Schwann cells to use the vascular scaffold to migrate within the adult nervous system. Nevertheless, more functional studies should be performed to address this question.

\section{Conclusion /perspectives}

Important to mention, numerous studies have shown extensive intercellular communication and coordinated interaction between the vascular and the nervous systems (Glebova \& Ginty, 2005; Park, Choi, Kim, \& Kim, 2003). Elucidating in part the mechanism that opens Schwann cell access to the damage CNS, we demonstrated that this Schwann cell-blood vessel interaction is of relevance to their contribution to CNS repair (Garcia-Diaz et al., 2019).

Over the last years, the role of angiogenesis and vascular remodeling in demyelinating disease has been explored focusing on their correlation with inflammation, neurogenesis, and oligodendroglia maturation (Girolamo, Coppola, Ribatti, \& Trojano, 2014; Kirk, Frank, \& Karlik, 2004; Lengfeld, Cutforth, \& Agalliu, 2014; Roscoe, Welsh, Carter, \& Karlik, 2009). Other studies brought to light the importance of the perivascular niche in the balance of Schwann cell/oligodendrocyte in the remyelination of the CNS lesion (Ulanska-Poutanen et al., 2018). Our study reveals another important aspect of this response to injury, the role of the vasculature dynamics in the repair of the lesioned CNS by Schwann cells (Garcia-Diaz et al., 2019). In spite of these observations, whether angiogenesis or remodeling of blood vessels open the astrocytic barrier to free Schwann cells from the astrocytic confinement remains to be investigated.

Moreover, the formation of new vessels brings to play other components such as pericytes, which are of relevance for CNS remyelination (De La Fuente et al., 2017). To add, angiogenesis also increases the blood vessel permeability (Dvorak, Brown, Detmar, \& Dvorak, 1995) to new molecules such as chemokines and trophic factors that will change the lesion microenvironment and further enhance Schwann cell recruitment by the injured site. These new specific microenvironments will provide different signals for cell recruitment/trans-differentiation in the lesion, or supply blood/serum components (cytokines, growth factors, oxygen, nutrients, etc...). Although the spectrum of these signals that induce myelinating cell recruitment or differentiation are still poorly understood, some leads start to emerge. For example, TGF- $\beta$ produced by microglial cells and/or by macrophages and profusely present in lesions, is a powerful mitogen for Schwann cells and plays a role in the production of extracellular matrix (reviewed in ( $\mathrm{Li}, \mathrm{Gu}, \& \mathrm{Yi}, 2017)$. To add, a recent study showed that macrophage activation boosts Schwann cell infiltration and remyelination within the lysolecithin lesion (Church, Milich, Lerch, Popovich, \& McTigue, 2017). However, whether this effect on Schwann cells is direct or indirect remains unsolved as macrophage activation promoted also axon survival and oligodendrocyte remyelination.

Our study also shows that EphrinB3 in myelin favors the adhesion and migration of these cells onto ECM via Integrin $\beta 1$, while Schwann cell adhesion in the absence of ECM is impaired (Garcia-Diaz et al., 2019). This aspect elucidates another component of the balance between oligodendrocyte and 
Schwann cell remyelination of the lesioned CNS. While EphrinB3 impairs the differentiation of oligodendrocyte precursor cells into mature competent myelinating cells (Syed et al., 2016), it favors Schwann cell mobilization towards the lesion.

In conclusion, studies over the recent years have elucidated major aspects of Schwann cell transgression of the PNS-CNS border to repair the CNS (Fig. 3). In spite of gaining a clearer view of this scenario, several features remain to be uncovered. Are blood vessels the only route of migration across the CNS? or, can this pathway be extended to the lymphatic system? Are these routes the same regardless Schwann cell peripheral or central origin, and are they scaffold for the formation of schwannomas around cranial and spinal nerves (Suresh et al., 2003)? So far non-myelinating and myelinating Schwann cells participate to CNS repair. Stem cells are also present in the adult PNS and namely in the adult DRG (reviewed in (Mehrotra, Tseropoulos, Bronner, \& Andreadis, 2019)). Yet their activation and involvement in response to CNS injury remains to be addressed. Is the stage of Schwann cell differentiation, which modulates their incursion during injury, of developmental relevance? How can this be therapeutically modeled to favor the CNS repair? Moreover, the close relation with blood vessels opens up an easy access for those cells to sense different local and systemic signals, which might influence their remyelinating success or failure. These are some of the questions that may provide important clues for the future. Novel lineage specific tools will be required to decipher these questions and to design successful therapies. 


\section{References}

Adelman, L. S., \& Aronson, S. M. (1972). Intramedullary nerve fiber and Schwann cell proliferation within the spinal cord (schwannosis). Neurology, 22(7), 726-731. doi: 10.1212/wnl.22.7.726

Afshari, F. T., Kwok, J. C., \& Fawcett, J. W. (2010). Astrocyte-produced ephrins inhibit schwann cell migration via VAV2 signaling. J Neurosci, 30(12), 4246-4255. doi: 10.1523/JNEUROSCI.335109.2010

Anderson, K. D., Guest, J. D., Dietrich, W. D., Bartlett Bunge, M., Curiel, R., Dididze, M., . . Levi, A. D. (2017). Safety of Autologous Human Schwann Cell Transplantation in Subacute Thoracic Spinal Cord Injury. J Neurotrauma, 34(21), 2950-2963. doi: 10.1089/neu.2016.4895

Andrews, M. R., \& Stelzner, D. J. (2007). Evaluation of olfactory ensheathing and schwann cells after implantation into a dorsal injury of adult rat spinal cord. J Neurotrauma, 24(11), 1773-1792. doi: 10.1089/neu.2007.0353

Assinck, P., Duncan, G. J., Plemel, J. R., Lee, M. J., Stratton, J. A., Manesh, S. B., . . Tetzlaff, W. (2017). Myelinogenic Plasticity of Oligodendrocyte Precursor Cells following Spinal Cord Contusion Injury. J Neurosci, 37(36), 8635-8654. doi: 10.1523/JNEUROSCI.2409-16.2017

Assouline, J. G., Bosch, P., Lim, R., Kim, I. S., Jensen, R., \& Pantazis, N. J. (1987). Rat astrocytes and Schwann cells in culture synthesize nerve growth factor-like neurite-promoting factors. Brain Res, 428(1), 103-118. doi: 10.1016/0165-3806(87)90087-3

Avellana-Adalid, V., Bachelin, C., Lachapelle, F., Escriou, C., Ratzkin, B., \& Baron-Van Evercooren, A. (1998). In vitro and in vivo behaviour of NDF-expanded monkey Schwann cells. Eur J Neurosci, 10(1), 291-300.

Bachelin, C., Lachapelle, F., Girard, C., Moissonnier, P., Serguera-Lagache, C., Mallet, J., . . Baron-Van Evercooren, A. (2005). Efficient myelin repair in the macaque spinal cord by autologous grafts of Schwann cells. Brain, 128(Pt 3), 540-549. doi: 10.1093/brain/awh406

Bachelin, C., Zujovic, V., Buchet, D., Mallet, J., \& Baron-Van Evercooren, A. (2010). Ectopic expression of polysialylated neural cell adhesion molecule in adult macaque Schwann cells promotes their migration and remyelination potential in the central nervous system. Brain, 133(Pt 2), 406-420. doi: 10.1093/brain/awp256

Bampton, E. T., \& Taylor, J. S. (2005). Effects of Schwann cell secreted factors on PC12 cell neuritogenesis and survival. J Neurobiol, 63(1), 29-48. doi: 10.1002/neu.20119

Baron-Van Evercooren, A., Avellana-Adalid, V., Ben Younes-Chennoufi, A., Gansmuller, A., NaitOumesmar, B., \& Vignais, L. (1996). Cell-cell interactions during the migration of myelinforming cells transplanted in the demyelinated spinal cord. Glia, 16(2), 147-164. doi: 10.1002/(SICI)1098-1136(199602)16:2<147::AID-GLIA7>3.0.CO;2-0

Baron-Van Evercooren, A., Clerin-Duhamel, E., Lapie, P., Gansmuller, A., Lachapelle, F., \& Gumpel, M. (1992). The fate of Schwann cells transplanted in the brain during development. Dev Neurosci, 14(2), 73-84. doi: 10.1159/000111650

Baron-Van Evercooren, A., Duhamel-Clerin, E., Boutry, J. M., Hauw, J. J., \& Gumpel, M. (1993). Pathways of migration of transplanted Schwann cells in the demyelinated mouse spinal cord. J Neurosci Res, 35(4), 428-438. doi: 10.1002/jnr.490350410

Baron-Van Evercooren, A., Kleinman, H. K., Seppa, H. E., Rentier, B., \& Dubois-Dalcq, M. (1982). Fibronectin promotes rat Schwann cell growth and motility. J Cell Biol, 93(1), 211-216. doi: 10.1083/jcb.93.1.211 
Bastidas, J., Athauda, G., De La Cruz, G., Chan, W. M., Golshani, R., Berrocal, Y., . . Pearse, D. D. (2017). Human Schwann cells exhibit long-term cell survival, are not tumorigenic and promote repair when transplanted into the contused spinal cord. Glia, 65(8), 1278-1301. doi: 10.1002/glia.23161

Black, J. A., Waxman, S. G., \& Smith, K. J. (2006). Remyelination of dorsal column axons by endogenous Schwann cells restores the normal pattern of Nav1.6 and Kv1.2 at nodes of Ranvier. Brain, 129(Pt 5), 1319-1329. doi: 10.1093/brain/awl057

Blakemore, W. F. (1982). Ethidium bromide induced demyelination in the spinal cord of the cat. Neuropathol Appl Neurobiol, 8(5), 365-375.

Blakemore, W. F., Crang, A. J., \& Patterson, R. C. (1987). Schwann cell remyelination of CNS axons following injection of cultures of CNS cells into areas of persistent demyelination. Neurosci Lett, 77(1), 20-24. doi: 10.1016/0304-3940(87)90600-8

Blakemore, W. F., \& Patterson, R. C. (1975). Observations on the interactions of Schwann cells and astrocytes following X-irradiation of neonatal rat spinal cord. J Neurocytol, 4(5), 573-585.

Blight, A. R., \& Young, W. (1989). Central axons in injured cat spinal cord recover electrophysiological function following remyelination by Schwann cells. J Neurol Sci, 91(1-2), 15-34.

Brook, G. A., Lawrence, J. M., \& Raisman, G. (1993). Morphology and migration of cultured Schwann cells transplanted into the fimbria and hippocampus in adult rats. Glia, 9(4), 292-304. doi: 10.1002/glia.440090407

Bunge, R. P. (1993). Expanding roles for the Schwann cell: ensheathment, myelination, trophism and regeneration. Curr Opin Neurobiol, 3(5), 805-809.

Casella, G. T., Bunge, R. P., \& Wood, P. M. (1996). Improved method for harvesting human Schwann cells from mature peripheral nerve and expansion in vitro. Glia, 17(4), 327-338. doi: 10.1002/(SICI)1098-1136(199608)17:4<327::AID-GLIA7>3.0.CO;2-W

Cattin, A. L., Burden, J. J., Van Emmenis, L., Mackenzie, F. E., Hoving, J. J., Garcia Calavia, N., . . Lloyd, A. C. (2015). Macrophage-Induced Blood Vessels Guide Schwann Cell-Mediated Regeneration of Peripheral Nerves. Cell, 162(5), 1127-1139. doi: 10.1016/j.cell.2015.07.021

Chaudhry, N., Bachelin, C., Zujovic, V., Hilaire, M., Baldwin, K. T., Follis, R. M., . . Filbin, M. T. (2017). Myelin-Associated Glycoprotein Inhibits Schwann Cell Migration and Induces Their Death. J Neurosci, 37(24), 5885-5899. doi: 10.1523/JNEUROSCI.1822-16.2017

Chiu, A. Y., Espinosa de los Monteros, A., Cole, R. A., Loera, S., \& de Vellis, J. (1991). Laminin and slaminin are produced and released by astrocytes, Schwann cells, and schwannomas in culture. Glia, 4(1), 11-24. doi: 10.1002/glia.440040103

Church, J. S., Milich, L. M., Lerch, J. K., Popovich, P. G., \& McTigue, D. M. (2017). E6020, a synthetic TLR4 agonist, accelerates myelin debris clearance, Schwann cell infiltration, and remyelination in the rat spinal cord. Glia, 65(6), 883-899. doi: 10.1002/glia.23132

Coulpier, F., Decker, L., Funalot, B., Vallat, J. M., Garcia-Bragado, F., Charnay, P., \& Topilko, P. (2011). Krox20 inactivation in the PNS leads to CNS/PNS boundary transgression by central glia. Rev Neurol (Paris), 167(1), 51-56. doi: 10.1016/j.neurol.2010.07.043

Dal Canto, M. C., \& Lipton, H. L. (1980). Schwann cell remyelination and recurrent demyelination in the central nervous system of mice infected with attenuated Theiler's virus. Am J Pathol, 98(1), 101-122.

De La Fuente, A. G., Lange, S., Silva, M. E., Gonzalez, G. A., Tempfer, H., van Wijngaarden, P., . . . Rivera, F. J. (2017). Pericytes Stimulate Oligodendrocyte Progenitor Cell Differentiation during CNS Remyelination. Cell Rep, 20(8), 1755-1764. doi: 10.1016/j.celrep.2017.08.007

Deng, L. X., Walker, C., \& Xu, X. M. (2015). Schwann cell transplantation and descending propriospinal regeneration after spinal cord injury. Brain Res, 1619, 104-114. doi: 10.1016/j.brainres.2014.09.038

Duffy, P., Wang, X., Siegel, C. S., Tu, N., Henkemeyer, M., Cafferty, W. B., \& Strittmatter, S. M. (2012). Myelin-derived ephrinB3 restricts axonal regeneration and recovery after adult CNS injury. Proc Natl Acad Sci U S A, 109(13), 5063-5068. doi: 10.1073/pnas.1113953109 
Duncan, I. D., Hammang, J. P., \& Gilmore, S. A. (1988). Schwann cell myelination of the myelin deficient rat spinal cord following X-irradiation. Glia, 1(3), 233-239. doi: 10.1002/glia.440010309

Duncan, I. D., \& Hoffman, R. L. (1997). Schwann cell invasion of the central nervous system of the myelin mutants. J Anat, 190 ( Pt 1), 35-49.

Dvorak, H. F., Brown, L. F., Detmar, M., \& Dvorak, A. M. (1995). Vascular permeability factor/vascular endothelial growth factor, microvascular hyperpermeability, and angiogenesis. Am J Pathol, 146(5), 1029-1039.

Emery, B. (2010). Regulation of oligodendrocyte differentiation and myelination. Science, 330(6005), 779-782. doi: 10.1126/science.1190927

Fairless, R., Frame, M. C., \& Barnett, S. C. (2005). N-cadherin differentially determines Schwann cell and olfactory ensheathing cell adhesion and migration responses upon contact with astrocytes. Mol Cell Neurosci, 28(2), 253-263. doi: 10.1016/j.mcn.2004.09.009

Feigin, I., \& Ogata, J. (1971). Schwann cells and peripheral myelin within human central nervous tissues: the mesenchymal character of Schwann cells. J Neuropathol Exp Neurol, 30(4), 603612. doi: 10.1097/00005072-197110000-00005

Felts, P. A., \& Smith, K. J. (1992). Conduction properties of central nerve fibers remyelinated by Schwann cells. Brain Res, 574(1-2), 178-192. doi: 10.1016/0006-8993(92)90815-q

Fishman, P. S., Nilaver, G., \& Kelly, J. P. (1983). Astrogliosis limits the integration of peripheral nerve grafts into the spinal cord. Brain Res, 277(1), 175-180. doi: 10.1016/0006-8993(83)90922-8

Fontenas, L., \& Kucenas, S. (2018). Motor Exit Point (MEP) Glia: Novel Myelinating Glia That Bridge CNS and PNS Myelin. Front Cell Neurosci, 12, 333. doi: 10.3389/fncel.2018.00333

Fraher, J. P. (1992). The CNS-PNS transitional zone of the rat. Morphometric studies at cranial and spinal levels. Prog Neurobiol, 38(3), 261-316.

Fraher, J. P. (1999). The transitional zone and CNS regeneration. J Anat, 194(Pt 2), 161-182. doi: 10.1046/j.1469-7580.1999.19420161.x

Fraher, J. P., \& Kaar, G. F. (1986). The lumbar ventral root-spinal cord transitional zone in the rat. A morphological study during development and at maturity. J Anat, 145, 109-122.

Fraher, J. P., \& Rossiter, J. P. (1983). Cell clusters on rat ventral roots: postnatal development. J Anat, 137 (Pt 3), 555-571.

Franklin, R. J., \& Blakemore, W. F. (1993). Requirements for Schwann cell migration within CNS environments: a viewpoint. Int J Dev Neurosci, 11(5), 641-649.

Garcia-Diaz, B., Bachelin, C., Coulpier, F., Gerschenfeld, G., Deboux, C., Zujovic, V., . . Baron-Van Evercooren, A. (2019). Blood vessels guide Schwann cell migration in the adult demyelinated CNS through Eph/ephrin signaling. Acta Neuropathol. doi: 10.1007/s00401-019-02011-1

Ghirnikar, R. S., \& Eng, L. F. (1994). Astrocyte-Schwann cell interactions in culture. Glia, 11(4), 367377. doi: $10.1002 / g l i a .440110409$

Ghirnikar, R. S., \& Eng, L. F. (1995). Chondroitin sulfate proteoglycan staining in astrocyte-Schwann cell co-cultures. Glia, 14(2), 145-152. doi: 10.1002/glia.440140209

Gilmore, S. A. (1971). Autoradiographic studies of intramedullary Schwann cells in irradiated spinal cords of immature rats. Anat Rec, 171(4), 517-528. doi: 10.1002/ar.1091710408

Gilmore, S. A., \& Sims, T. J. (1993). Patterns of Schwann cell myelination of axons within the spinal cord. J Chem Neuroanat, 6(4), 191-199.

Gilmore, S. A., \& Sims, T. J. (1997). Glial-glial and glial-neuronal interfaces in radiation-induced, gliadepleted spinal cord. J Anat, 190 ( Pt 1), 5-21. doi: 10.1046/j.1469-7580.1997.19010005.x

Gilmore, S. A., Sims, T. J., \& Heard, J. K. (1982). Autoradiographic and ultrastructural studies of areas of spinal cord occupied by Schwann cells and Schwann cell myelin. Brain Res, 239(2), 365375. doi: 10.1016/0006-8993(82)90515-7

Girard, C., Bemelmans, A. P., Dufour, N., Mallet, J., Bachelin, C., Nait-Oumesmar, B., . . Lachapelle, F. (2005). Grafts of brain-derived neurotrophic factor and neurotrophin 3-transduced primate Schwann cells lead to functional recovery of the demyelinated mouse spinal cord. J Neurosci, 25(35), 7924-7933. doi: 10.1523/JNEUROSCI.4890-04.2005 
Girolamo, F., Coppola, C., Ribatti, D., \& Trojano, M. (2014). Angiogenesis in multiple sclerosis and experimental autoimmune encephalomyelitis. Acta Neuropathol Commun, 2, 84. doi: 10.1186/s40478-014-0084-z

Glebova, N. O., \& Ginty, D. D. (2005). Growth and survival signals controlling sympathetic nervous system development. Annu Rev Neurosci, 28, 191-222. doi: 10.1146/annurev.neuro.28.061604.135659

Griffiths, I. R., \& McCulloch, M. C. (1983). Nerve fibres in spinal cord impact injuries. Part 1. Changes in the myelin sheath during the initial 5 weeks. J Neurol Sci, 58(3), 335-349.

Grimpe, B., Pressman, Y., Lupa, M. D., Horn, K. P., Bunge, M. B., \& Silver, J. (2005). The role of proteoglycans in Schwann cell/astrocyte interactions and in regeneration failure at PNS/CNS interfaces. Mol Cell Neurosci, 28(1), 18-29. doi: 10.1016/j.mcn.2004.06.010

Guest, J., Santamaria, A. J., \& Benavides, F. D. (2013). Clinical translation of autologous Schwann cell transplantation for the treatment of spinal cord injury. Curr Opin Organ Transplant, 18(6), 682-689. doi: 10.1097/МOT.0000000000000026

Guest, J. D., Hiester, E. D., \& Bunge, R. P. (2005). Demyelination and Schwann cell responses adjacent to injury epicenter cavities following chronic human spinal cord injury. Exp Neurol, 192(2), 384-393. doi: 10.1016/j.expneurol.2004.11.033

Heard, J. K., \& Gilmore, S. A. (1980). Intramedullary Schwann cell development following x-irradiation of mid-thoracic and lumbosacral spinal cord levels in immature rats. Anat Rec, 197(1), 85-93. doi: 10.1002/ar.1091970108

Itoyama, Y., Ohnishi, A., Tateishi, J., Kuroiwa, Y., \& Webster, H. D. (1985). Spinal cord multiple sclerosis lesions in Japanese patients: Schwann cell remyelination occurs in areas that lack glial fibrillary acidic protein (GFAP). Acta Neuropathol, 65(3-4), 217-223.

Itoyama, Y., Webster, H. D., Richardson, E. P., Jr., \& Trapp, B. D. (1983). Schwann cell remyelination of demyelinated axons in spinal cord multiple sclerosis lesions. Ann Neurol, 14(3), 339-346. doi: 10.1002/ana.410140313

Iwashita, Y., \& Blakemore, W. F. (2000). Areas of demyelination do not attract significant numbers of schwann cells transplanted into normal white matter. Glia, 31(3), 232-240.

Iwashita, Y., Fawcett, J. W., Crang, A. J., Franklin, R. J., \& Blakemore, W. F. (2000). Schwann cells transplanted into normal and X-irradiated adult white matter do not migrate extensively and show poor long-term survival. Exp Neurol, 164(2), 292-302. doi: 10.1006/exnr.2000.7440

Jasmin, L., Janni, G., Moallem, T. M., Lappi, D. A., \& Ohara, P. T. (2000). Schwann cells are removed from the spinal cord after effecting recovery from paraplegia. J Neurosci, 20(24), 9215-9223.

Jessen, K. R., \& Mirsky, R. (2005). The origin and development of glial cells in peripheral nerves. Nat Rev Neurosci, 6(9), 671-682. doi: 10.1038/nrn1746

Jessen, K. R., \& Mirsky, R. (2019). The Success and Failure of the Schwann Cell Response to Nerve Injury. Front Cell Neurosci, 13, 33. doi: 10.3389/fncel.2019.00033

Kanno, H., Pearse, D. D., Ozawa, H., Itoi, E., \& Bunge, M. B. (2015). Schwann cell transplantation for spinal cord injury repair: its significant therapeutic potential and prospectus. Rev Neurosci, 26(2), 121-128. doi: 10.1515/revneuro-2014-0068

Kirk, S., Frank, J. A., \& Karlik, S. (2004). Angiogenesis in multiple sclerosis: is it good, bad or an epiphenomenon? J Neurol Sci, 217(2), 125-130. doi: 10.1016/j.jns.2003.10.016

Kocsis, J. D., Akiyama, Y., Lankford, K. L., \& Radtke, C. (2002). Cell transplantation of peripheralmyelin-forming cells to repair the injured spinal cord. J Rehabil Res Dev, 39(2), 287-298.

Kocsis, J. D., \& Waxman, S. G. (2007). Schwann cells and their precursors for repair of central nervous system myelin. Brain, 130(Pt 8), 1978-1980. doi: 10.1093/brain/awm161

Lakatos, A., Barnett, S. C., \& Franklin, R. J. (2003). Olfactory ensheathing cells induce less host astrocyte response and chondroitin sulphate proteoglycan expression than Schwann cells following transplantation into adult CNS white matter. Exp Neurol, 184(1), 237-246. doi: 10.1016/s0014-4886(03)00270-x

Lakatos, A., Franklin, R. J., \& Barnett, S. C. (2000). Olfactory ensheathing cells and Schwann cells differ in their in vitro interactions with astrocytes. Glia, 32(3), 214-225. 
Langford, L. A., \& Owens, G. C. (1990). Resolution of the pathway taken by implanted Schwann cells to a spinal cord lesion by prior infection with a retrovirus encoding beta-galactosidase. Acta Neuropathol, 80(5), 514-520.

Lavdas, A. A., Franceschini, I., Dubois-Dalcq, M., \& Matsas, R. (2006). Schwann cells genetically engineered to express PSA show enhanced migratory potential without impairment of their myelinating ability in vitro. Glia, 53(8), 868-878. doi: 10.1002/glia.20340

Le, N., Nagarajan, R., Wang, J. Y., Araki, T., Schmidt, R. E., \& Milbrandt, J. (2005). Analysis of congenital hypomyelinating Egr2Lo/Lo nerves identifies Sox2 as an inhibitor of Schwann cell differentiation and myelination. Proc Natl Acad Sci U S A, 102(7), 2596-2601. doi: 10.1073/pnas.0407836102

Lengfeld, J., Cutforth, T., \& Agalliu, D. (2014). The role of angiogenesis in the pathology of multiple sclerosis. Vasc Cell, 6(1), 23. doi: 10.1186/s13221-014-0023-6

Levi, A. D., Bunge, R. P., Lofgren, J. A., Meima, L., Hefti, F., Nikolics, K., \& Sliwkowski, M. X. (1995). The influence of heregulins on human Schwann cell proliferation. J Neurosci, 15(2), 1329-1340.

Li, S., Gu, X., \& Yi, S. (2017). The Regulatory Effects of Transforming Growth Factor-beta on Nerve Regeneration. Cell Transplant, 26(3), 381-394. doi: 10.3727/096368916X693824

Ma, D., Wang, B., Zawadzka, M., Gonzalez, G., Wu, Z., Yu, B., . . Zhao, C. (2018). A Subpopulation of Foxj1-Expressing, Nonmyelinating Schwann Cells of the Peripheral Nervous System Contribute to Schwann Cell Remyelination in the Central Nervous System. J Neurosci, 38(43), 9228-9239. doi: 10.1523/JNEUROSCI.0585-18.2018

Mehrotra, P., Tseropoulos, G., Bronner, M. E., \& Andreadis, S. T. (2019). Adult tissue-derived neural crest-like stem cells: Sources, regulatory networks, and translational potential: Concise review. Stem Cells Trans/ Med. doi: 10.1002/sctm.19-0173

Milner, R., Wilby, M., Nishimura, S., Boylen, K., Edwards, G., Fawcett, J., . . . ffrench-Constant, C. (1997). Division of labor of Schwann cell integrins during migration on peripheral nerve extracellular matrix ligands. Dev Biol, 185(2), 215-228. doi: 10.1006/dbio.1997.8547

Monteiro de Castro, G., Deja, N. A., Ma, D., Zhao, C., \& Franklin, R. J. (2015). Astrocyte Activation via Stat3 Signaling Determines the Balance of Oligodendrocyte versus Schwann Cell Remyelination. Am J Pathol, 185(9), 2431-2440. doi: 10.1016/j.ajpath.2015.05.011

O'Neill, P., Lindsay, S. L., Pantiru, A., Guimond, S. E., Fagoe, N., Verhaagen, J., . . Barnett, S. C. (2017). Sulfatase-mediated manipulation of the astrocyte-Schwann cell interface. Glia, 65(1), 19-33. doi: 10.1002/glia.23047

Papastefanaki, F., Chen, J., Lavdas, A. A., Thomaidou, D., Schachner, M., \& Matsas, R. (2007). Grafts of Schwann cells engineered to express PSA-NCAM promote functional recovery after spinal cord injury. Brain, 130(Pt 8), 2159-2174. doi: 10.1093/brain/awm155

Park, J. A., Choi, K. S., Kim, S. Y., \& Kim, K. W. (2003). Coordinated interaction of the vascular and nervous systems: from molecule- to cell-based approaches. Biochem Biophys Res Commun, 311(2), 247-253.

Pearse, D. D., Marcillo, A. E., Oudega, M., Lynch, M. P., Wood, P. M., \& Bunge, M. B. (2004). Transplantation of Schwann cells and olfactory ensheathing glia after spinal cord injury: does pretreatment with methylprednisolone and interleukin-10 enhance recovery? J Neurotrauma, 21(9), 1223-1239. doi: 10.1089/neu.2004.21.1223

Pearse, D. D., Sanchez, A. R., Pereira, F. C., Andrade, C. M., Puzis, R., Pressman, Y., . . Bunge, M. B. (2007). Transplantation of Schwann cells and/or olfactory ensheathing glia into the contused spinal cord: Survival, migration, axon association, and functional recovery. Glia, 55(9), 9761000. doi: $10.1002 / g l i a .20490$

Plant, G. W., Bates, M. L., \& Bunge, M. B. (2001). Inhibitory proteoglycan immunoreactivity is higher at the caudal than the rostral Schwann cell graft-transected spinal cord interface. Mol Cell Neurosci, 17(3), 471-487. doi: 10.1006/mcne.2000.0948

Raine, C. S. (1976). On the occurrence of Schwann cells within the normal central nervous system. $J$ Neurocytol, 5(3), 371-380. 
Raine, C. S., Traugott, U., \& Stone, S. H. (1978). Glial bridges and Schwann cell migration during chronic demyelination in the C.N.S. J Neurocytol, 7(5), 541-553.

Raisman, G., Lawrence, J. M., \& Brook, G. A. (1993). Schwann cells transplanted into the CNS. Int J Dev Neurosci, 11(5), 651-669.

Reichardt, L. F., Bixby, J. L., Hall, D. E., Ignatius, M. J., Neugebauer, K. M., \& Tomaselli, K. J. (1989). Integrins and cell adhesion molecules: neuronal receptors that regulate axon growth on extracellular matrices and cell surfaces. Dev Neurosci, 11(4-5), 332-347. doi: 10.1159/000111910

Richardson, P. M., Issa, V. M., \& Shemie, S. (1982). Regeneration and retrograde degeneration of axons in the rat optic nerve. J Neurocytol, 11(6), 949-966.

Roscoe, W. A., Welsh, M. E., Carter, D. E., \& Karlik, S. J. (2009). VEGF and angiogenesis in acute and chronic MOG((35-55)) peptide induced EAE. J Neuroimmunol, 209(1-2), 6-15. doi: 10.1016/j.jneuroim.2009.01.009

Rutkowski, J. L., Kirk, C. J., Lerner, M. A., \& Tennekoon, G. I. (1995). Purification and expansion of human Schwann cells in vitro. Nat Med, 1(1), 80-83.

Santos-Silva, A., Fairless, R., Frame, M. C., Montague, P., Smith, G. M., Toft, A., . . Barnett, S. C. (2007). FGF/heparin differentially regulates Schwann cell and olfactory ensheathing cell interactions with astrocytes: a role in astrocytosis. I Neurosci, 27(27), 7154-7167. doi: 10.1523/JNEUROSCI.1184-07.2007

Shields, S. A., Blakemore, W. F., \& Franklin, R. J. (2000). Schwann cell remyelination is restricted to astrocyte-deficient areas after transplantation into demyelinated adult rat brain. J Neurosci Res, 60(5), 571-578. doi: 10.1002/(SICI)1097-4547(20000601)60:5<571::AID-JNR1>3.0.CO;2Q

Sims, T. J., Durgun, M. B., \& Gilmore, S. A. (1998). Schwann cell invasion of ventral spinal cord: the effect of irradiation on astrocyte barriers. J Neuropathol Exp Neurol, 57(9), 866-873. doi: 10.1097/00005072-199809000-00008

Sparling, J. S., Bretzner, F., Biernaskie, J., Assinck, P., Jiang, Y., Arisato, H., . . Tetzlaff, W. (2015). Schwann cells generated from neonatal skin-derived precursors or neonatal peripheral nerve improve functional recovery after acute transplantation into the partially injured cervical spinal cord of the rat. J Neurosci, 35(17), 6714-6730. doi: 10.1523/JNEUROSCI.1070-14.2015

Suresh, T. N., Mahadevan, A., Chandrashekhar Sagar, B., Santosh, V., Yasha, T. C., \& Shankar, S. K. (2003). Unusual case of multiple cellular and malignant schwannomas of the cranial and spinal nerves. Clin Neuropathol, 22(1), 23-29.

Syed, Y. A., Zhao, C., Mahad, D., Mobius, W., Altmann, F., Foss, F., . . Kotter, M. R. N. (2016). Antibody-mediated neutralization of myelin-associated EphrinB3 accelerates CNS remyelination. Acta Neuropathol, 131(2), 281-298. doi: 10.1007/s00401-015-1521-1

Talbott, J. F., Loy, D. N., Liu, Y., Qiu, M. S., Bunge, M. B., Rao, M. S., \& Whittemore, S. R. (2005). Endogenous Nkx2.2+/Olig2+ oligodendrocyte precursor cells fail to remyelinate the demyelinated adult rat spinal cord in the absence of astrocytes. Exp Neurol, 192(1), 11-24. doi: 10.1016/j.expneurol.2004.05.038

Ulanska-Poutanen, J., Mieczkowski, J., Zhao, C., Konarzewska, K., Kaza, B., Pohl, H. B., . . Zawadzka, M. (2018). Injury-induced perivascular niche supports alternative differentiation of adult rodent CNS progenitor cells. Elife, 7. doi: 10.7554/eLife.30325

Wang, Z. H., Walter, G. F., \& Gerhard, L. (1996). The expression of nerve growth factor receptor on Schwann cells and the effect of these cells on the regeneration of axons in traumatically injured human spinal cord. Acta Neuropathol, 91(2), 180-184.

Wei, Z., Fan, B., Ding, H., Liu, Y., Tang, H., Pan, D., . . Feng, S. (2019). Proteomics analysis of Schwann cell-derived exosomes: a novel therapeutic strategy for central nervous system injury. Mol Cell Biochem, 457(1-2), 51-59. doi: 10.1007/s11010-019-03511-0

Wilby, M. J., Muir, E. M., Fok-Seang, J., Gour, B. J., Blaschuk, O. W., \& Fawcett, J. W. (1999). NCadherin inhibits Schwann cell migration on astrocytes. Mol Cell Neurosci, 14(1), 66-84. doi: 10.1006/mcne.1999.0766 
Woodhoo, A., Sahni, V., Gilson, J., Setzu, A., Franklin, R. J., Blakemore, W. F., . . Jessen, K. R. (2007). Schwann cell precursors: a favourable cell for myelin repair in the Central Nervous System. Brain, 130(Pt 8), 2175-2185. doi: 10.1093/brain/awm125

Woodruff, R. H., \& Franklin, R. J. (1999). Demyelination and remyelination of the caudal cerebellar peduncle of adult rats following stereotaxic injections of lysolecithin, ethidium bromide, and complement/anti-galactocerebroside: a comparative study. Glia, 25(3), 216-228.

Yamamoto, T., Kawamura, J., Hashimoto, S., \& Nakamura, M. (1991). Extensive proliferation of peripheral type myelin in necrotic spinal cord lesions of multiple sclerosis. $J$ Neurol Sci, 102(2), 163-169.

Zawadzka, M., Rivers, L. E., Fancy, S. P., Zhao, C., Tripathi, R., Jamen, F., . . Franklin, R. J. (2010). CNSresident glial progenitor/stem cells produce Schwann cells as well as oligodendrocytes during repair of CNS demyelination. Cell Stem Cell, 6(6), 578-590. doi: 10.1016/j.stem.2010.04.002

Zujovic, V., Thibaud, J., Bachelin, C., Vidal, M., Coulpier, F., Charnay, P., . . Baron-Van Evercooren, A. (2010). Boundary cap cells are highly competitive for CNS remyelination: fast migration and efficient differentiation in PNS and CNS myelin-forming cells. Stem Cells, 28(3), 470-479. doi: 10.1002/stem.290

Zujovic, V., Thibaud, J., Bachelin, C., Vidal, M., Deboux, C., Coulpier, F., . . Baron-Van Evercooren, A. (2011). Boundary cap cells are peripheral nervous system stem cells that can be redirected into central nervous system lineages. Proc Natl Acad Sci U S A, 108(26), 10714-10719. doi: 10.1073/pnas.1018687108 


\section{Figure 1}

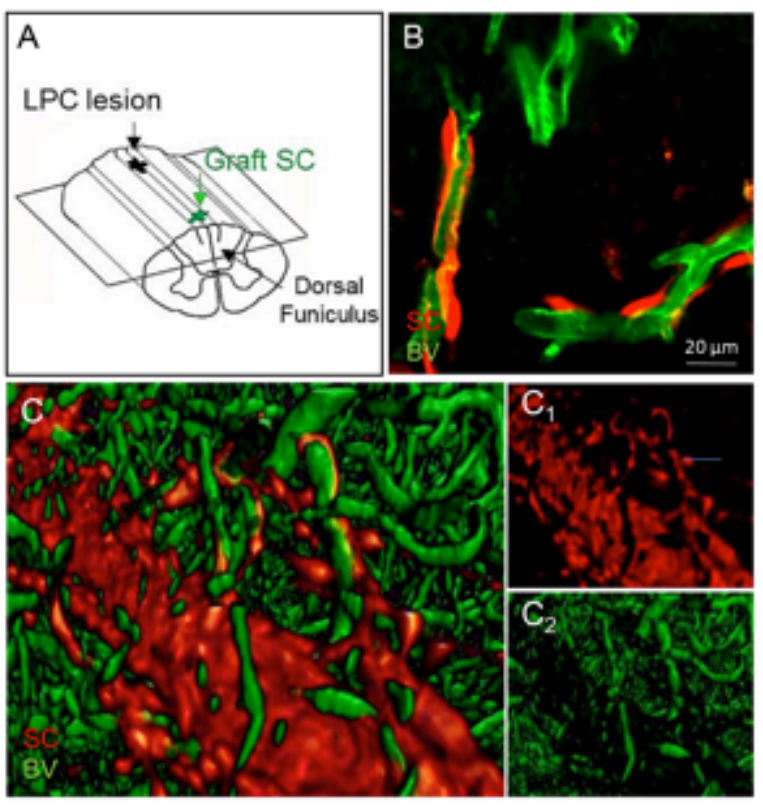

Figure 1. A. Scheme of LPC lesion and SC graft targeted into the dorsal funiculus of the spinal cord. B. 3D Z stack reconstruction illustrating grafted SC (red) around blood vessels (green); C. Clarified spinal cord showing grafted Schwann cells ( $\mathrm{SC}, \mathrm{C}_{1}$ ) expressing the Tomato Cherry protein (red) that migrate along blood vessels (green, $\mathrm{C}_{2}$ ). 


\section{Figure 2}
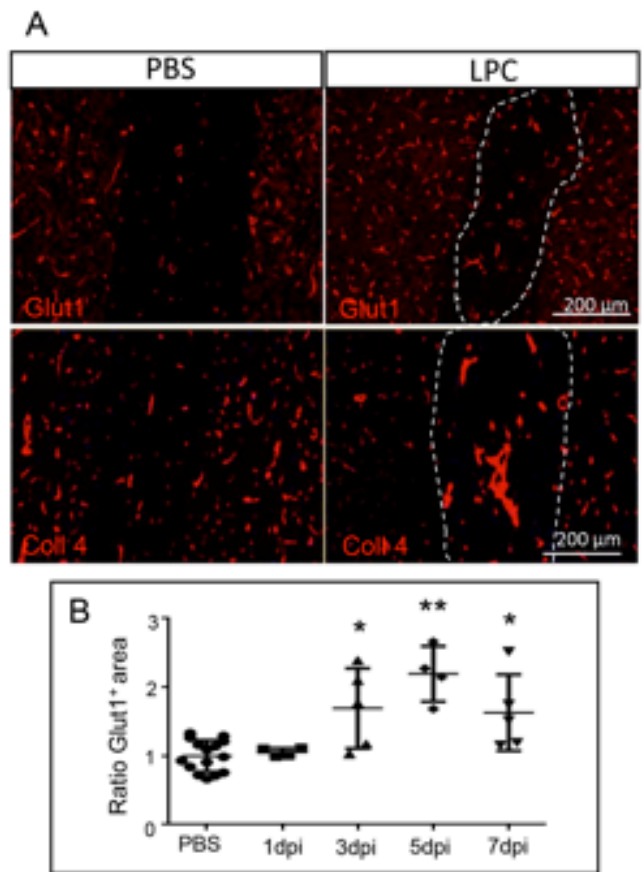

Figure 2. Vascular remodelling in response to lysolecithin-induced demyelination of the spinal cord. Demyelination was induced by lysolecithin injection into the dorsal funiculus of the mouse spinal cord. A Immunolabeling of the vasculature using the endothelial marker Glut1 (red) 5 days post injection lysolecithin (5dpi), shows that the vascular network increases within the lesion site (dotted line) concomitantly with an increase in the basal lamina marker collagen 4 (red) in the demyelinated lesion. B. Quantification of the vasculature dynamics at different time-points after LPC injection $(1,3$, 5 and $7 \mathrm{dpi}$ ) based on the ratio of Glut1+ area after LPC over PBS at 1dpi.) Data are expressed as mean value \pm SD of control (PBS) $(n=15), 1 \mathrm{dpi}(n=4)$, 3dpi $(n=4), 5 \mathrm{dpi}(n=4), 7 \mathrm{dpi}(n=5)$. Kruskal-Wallis test $(p=0.001)$ followed by comparison between each group with PBS group performed by two-tailed Mann Whitney test 3dpi ( $p=0.019) ; 5 d p i(p=0.0005)$; and 7dpi $(p=0.01)$. 


\section{Figure 3}

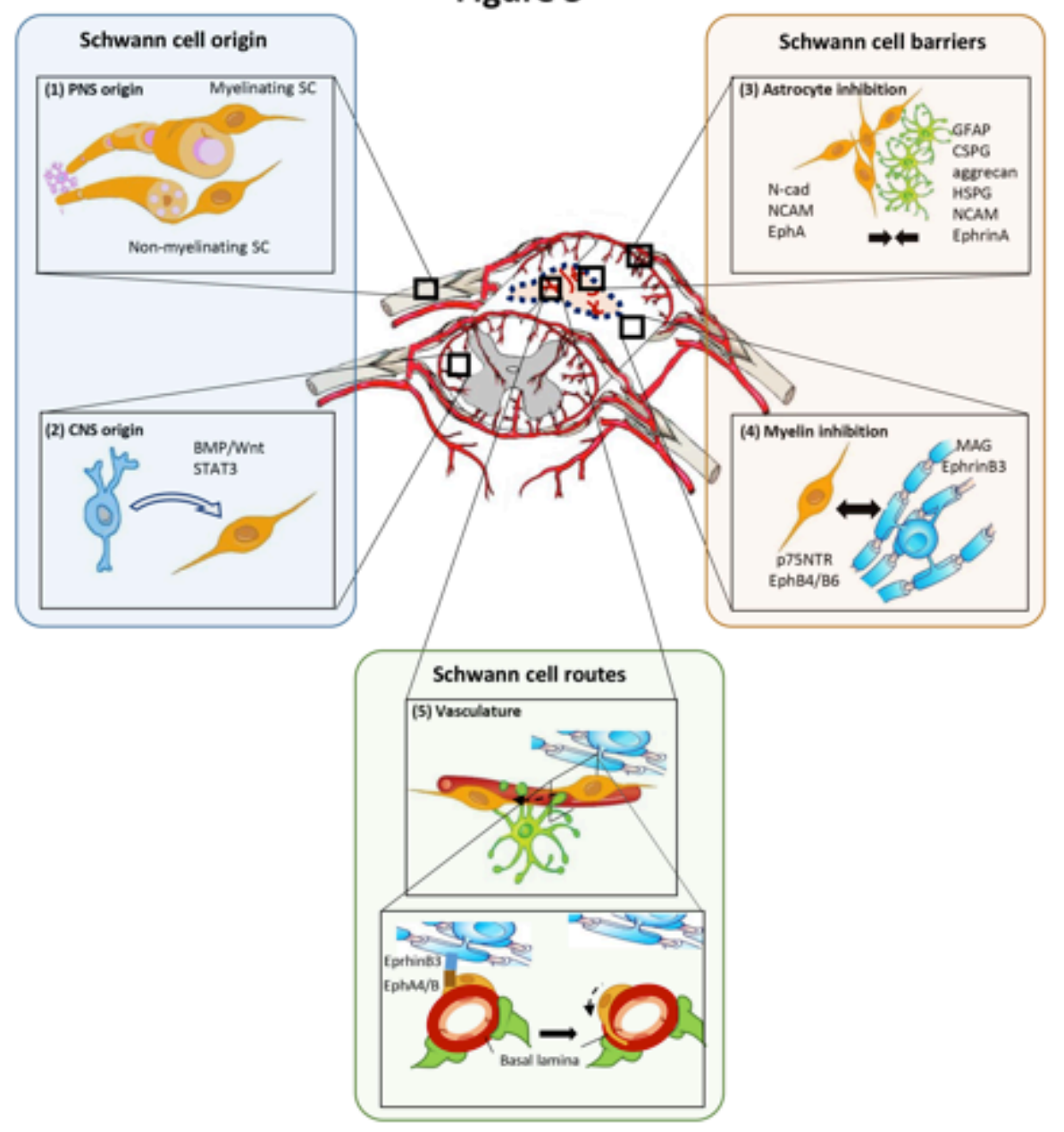

Figure 3. Graphical abstract on Schwann cell origins and interactions with CNS cell components. (1) CNS-located Schwann cells (yellow-brown cells) originate from the peripheral myelinating and nonmyelinating Schwann cells; (2) and the central transdifferentiated OPC (blue-grey cell) under BMP/Wnt and STAT3 signaling. (3) Schwann cell invasion of the CNS is impaired by astrocyte (green cells) at the level of the PNS-CNS transition zone (glia limitans) and the CNS lesion border (reactive astrocytes). Schwann cell-astrocyte repulsion is due to different components such as N-cad, NCAM, and EphAs in Schwann cells, and by GFAP, CSPG, aggrecan, HSPG, NCAM and EphrinAs in astrocytes. (4) Schwann cell migration within the CNS, is inhibited by myelin (blue), through MAG-p75NTR and EphrinB3-EphA4/B6 signaling. (5) Myelin-associated EphrinB3 modulates the adhesion of Schwann cells via upregulaion of Integring $\beta 1$, and thereby, increasing their affinity for ECM (red) migration on blood vessels (Garcia-Diaz et al., 2019). 
